6

\title{
Contracts in the IT Education of Managers
}

\author{
Bill Davey \\ RMIT \\ 239 Bourke Street \\ Melbourne, Victoria, Australia 3001 \\ ph: +61396605975 fax: +61396605850 \\ email:Billd@rmit.edu.au
}

\begin{abstract}
For several years the Department of Business Computing has been providing IT education to management courses at RMIT. One main course is the Graduate Diploma of Management which has a special requirement that only full time managers may enter. In addition a common thread is that the course is short (8 subjects) and only a small amount of time has been allowed for the IT component (1 subject).

The department has offered the subject through a contract system. This seems particularly apt to the situation and experience has shown some interesting results from the contract learning system which has implications for management IT education in general.

A striking finding over a number of groups is that, not only do these managers have little knowledge of IT skills applicable to their jobs, but the level of trust they put in "expert" advice is dissimilar to that applied to other aspects of their role.

The contract system has shown utility in providing for the needs of managers, but also in transfer of knowledge, continuation of learning after the cessation of formal studies and in the quality of student reflection of their learning experiences.

Examination of the contracts completed by students shows an interesting set of skills, attitudes and behaviours that become changed as the students apply learning to their work. These include changed perceptions of the talents of IT aware subordinates, increased awareness of the strategic possibilities of IT and enhanced understanding of the strengths and weaknesses of organisational IT infrastructure.
\end{abstract}

IT education, managers, contracts

\section{Keywords}

\section{INTRODUCTION}

The IT education of managers is normally constrained by many imponderables. Students often enrol in a generalised management course where small amounts of time 
are devoted to IT. Students are often at wildly different stages of IT background with differing levels of interest ranging from a desire to retrain down to a need for specific skills for a short term project. A method involving negotiated learning contracts has been tried at RMIT with a wide range of additional advantages over traditional fixed curricula. The experience at RMIT shows that several preconditions are required for a contract system to produce the best results.

\section{HOW DOES THE CONTRACT SYSTEM WORK}

The Graduate Diploma of management at RMIT is typical of much post graduate education for managers in that one subject is reserved for IT education. The degree is offered using a learning contract for each subject. Students are organised into Professional Development Teams (PDTs) of about 5 or 6 . For each subject the students decide upon a learning contract covering details such as learning experiences and outcomes or deliverables. These contracts must be negotiated with the other students in the PDT and with an academic consultant assigned to the PDT for each subject. Students are exposed to the range of material relevant to each subject during a weekend residential conference and generally choose material from within topics covered at the conference. Students have minima which must form part of their contract, but these are expressed in fairly general terms to enable contracts to be carried out with relevance to the student work situation. The assessment of completion of the contract is determined by the PDT and the academic consultant. The contract system, introduced by James Ford as the basis for the graduate diploma, has especial consequences for the IT component of management education.

Since the students must be practicing managers in order to be selected for the course all contracts are executed in the context of the students' work situation. This is particularly apt for management subjects but the idea of learning IT fundamentals might not seem as appropriate. After the initial introductory weekend, students are given a range of learning materials and opportunities throughout the semester. This continued support is essential if the student is not to become narrow in focus.

\section{REFLECTIONS ON CONTRACTING AS A LEARNING METHOD}

The IT subject is one of the first subjects in the diploma and so student confusion with the contract system is still apparent. The slow realisation that work will be immediately of use to the student, that learning will take place in the work situation and show immediate benefits, is very pleasant for educators normally removed by several years from the application of their subject matter. Contract negotiations normally involve discussion of upcoming projects in the students lives and the IT concepts relevant to those tasks. The task of the academic consultant is normally centred around scope. Students are either excited by the potential or daunted by their lack of skills, setting either very wide or extremely narrow scope for their contracts.

Part of the system for dealing with scope is the setting of minima. Students must include some IT fundamentals in their contracts. These minima have slowly increased in complexity with the increase in prior skills of students. Several years ago the minima 
included word processing skills. Today students must be able to submit by email and word processing is assumed.

The most satisfying aspect of the contract method is the immediate relevance of learning. Almost by definition students learning is transferable to their work lives. All learning takes place in the context of a work tasks of meaning to the student. Interviews with past students show that this has increased the extent to which learning continues after the course. As a corollary of this is the fun an academic has in matching IT fundamentals to the work situations of individuals. A typical academic load will be 5 PDTs, amounting to about 30 students. This means that PDT meetings require the academic consultant to apply IT fundamentals to 30 different work situations. The payback is when 30 students show at the end of the subject how they have applied the skills and knowledge to these projects. One of the principal philosophical bases for the system is to shift the responsibility for learning to the student. This is the only sensible place for that responsibility, but the contract system makes the balance of academic guidance and learning as clear cut as possible.

Project selection is obviously crucial to success. It is important to have students focus on successful learning rather than successful completion of the project. Often projects are delayed or derailed due to circumstances beyond the control of the student. Learning, however, can proceed even if it means that a submission results that is not put to the host organisation.

\section{REFLECTIONS ON MANAGERS IT NEEDS}

The subject team have been continuously conscious of a choice between traditional content choice and the contract system. In a traditional subject the choice of material is seen as being the sole responsibility of the academic with guidance from various quarters. The risk in a contract system is that the student will be enabled to narrow focus in the study to such an extent that the discipline is not seen as a whole and hence is misrepresented in the mind of the student. Another pressing problem for delivery of IT education is the problem of honestly representing the discipline within a very restricted time period. Typical contact hours for management courses can be as low as 24 hours for all the IT section. The risk of sending partly exposed students out of a management degree thinking they have a good grasp of the IT fundamentals seems high.

The group may not be representative of management in general but is typical of managers who both have a need for IT education and have done something about it. They exhibit consistent behaviours that can be explained in terms of myth and perception that can be instructive when approaching IT education issues.

The experiences arising from the delivery of this subject are not generalisable. Students have recognised their need for general education by enrolling in a graduate management course. The IT component of the course is inflicted upon them because it is a core subject. With this in mind, several interesting things about management IT education have arisen.

Firstly the level of IT awareness of our management students has risen steadily over the last few years. Students are no longer content to learn some word processing. They generally see IT skills as a prerequisite to attacking a class of problems in the workplace. They seem to almost universally recognise the need for database and general data management skills. Most contracts are now containing at least a prototype 
level of database skills. Another widely requested contract component is the use of IT in presentations. This normally means learning to capture data from a corporate source and learn how best to refine the data into an easily communicated format.

\section{INTERACTIONS BETWEEN MANAGERS AND IT PROFESSIONALS}

If IT education is to be effective it must be seen in the context of life education and hence the work environment of the students. The course, set in the students own work situation, has thrown light on the range of interactions between IT support personnel and management in general. An aspect that has surprised the academic leaders of the subject is the extent to which organisations have been creating barriers between managers and IT function. A large number of students report that the interaction between them and their IT support departments has gone through a set of stages from dismissal of the manager, through open conflict to eventual resolution between the manager and the IT professionals. Our students use their contracts to become better acquainted with their IT support sections. Their increased confidence also changes the power balance with students coming to recognise both the potential of a well structured information system, but also some of the imponderables involved in producing effective systems. This seems to be more real to students because their learning has taken place in the context of a project.

\section{CONCLUSION}

The experiences at RMIT have shown that contract systems can be very successful. They have also shown a range of factors that must be considered when delivering to managers if the IT education is to be successful. These include:

- increasing the awareness of possibilities in IT

- meaningful introductions to the main components of the discipline

- providing a support mechanism that will cope with work based learning

- having clear ideas of what is to be learnt

- creating a sense of responsibility for their own learning in students

Given these conditions, managers have found the contract system to cater for their needs and academic staff have the feeling that the learning that takes place is more effective.

\section{BIOGRAPHY}

Bill Davey is a senior lecturer in Business Computing from RMIT. He is interested in management education, particularly the implications of client-server technologies to executive information systems. Bill lectures in systems implementation, client-server systems, end-user computing and various computer languages. 